\title{
Un "trialogo" entre especialistas: Castells/ Subirats/García de león (sobre genero, familia, amor)
}

\author{
Mujeres y hombres ¿Un amor \\ imposible?
}

SUBIRATS, Marina; CASTELLS, Manuel.

Madrid: Alianza Ed., 2007. 320 p.
He aquí una idea feliz: las trescientas veinte páginas que Marina Subirats y Manuel Castells nos brindan, nada más ni nada menos que sobre Mujeres y Hombres ¿Un amor imposible?, libro reciente y muy bien editado por Alianza Editorial.

Ambos autores están "en el corazón de la vida". Podría seguir diciendo igualmente: en el eje, en el centro, o "bajo el volcán" (con reminiscencias literarias). En suma, ésta es una forma de subrayar que la relación masculino/ femenino es de tal manera fundamental que requiere dicho énfasis. El género es el gran factor estructurante-vertebrador de lo social, he escrito yo. En ello, parece haber acuerdo en la comunidad sociológica, hoy, y los propios autores, al hilo de afirmar que otro mundo es posible, dicen: "Y para que ese otro mundo sea posible de verdad, hay que empezar por los fundamentos, por una nueva relación entre hombres y mujeres. O sea, por usted y sus circunstancias. Por eso le invitamos a acompañarnos en nuestra exploración" (p. 13).

Ésta es la garbosa invitación que nos hacen los autores, que efectivamente tienen mucho de buenos exploradores, como lo demuestran adentrándose en el selvático paisaje de las relaciones de género. Machete en mano van desbrozando las miles de ramas, brotes nuevos, bifurcaciones y caminos por estrenar que crecen exuberantemente en torno al Género. Esta exploración a dúo la llevan a buen puerto, a través de una larga conversación que ocupa más de la mitad de la obra (desde la pág. 137 hasta el final). La conversación es tan viva, tan bien llevada, tan apasionante, además sobre uno de los "grandes temas de nuestro tiempo", "la cuestión palpitante" (por utilizar etiquetas clásicas) que rápidamente su lectura nos hace expedicionarios/as y, sin darnos tregua, cogemos el morral y la cantimplora, sumándonos a la arriesgada caravana Subirats/Castells.

Así de interesante es esta obra y este tema, tratado por dos miembros muy destacados del campo sociológico, tanto nacional como internacional. Se nota que lo han pasado bien discurriendo, hablando. Se advierte que el asunto les es vital, que creían en la necesidad y urgencia de este trabajo. Y nada hay mejor que esos ingredientes para que resulte una obra bien hecha, cuya lectura abre el apetito lector (se añade a ello, la excelente transcripción de la conversación y su formato que ha eliminado la conocida pesadez de lo oral: muletillas, imprecisiones, etc., etc.).

A dicha conversación, le anteceden dos capítulos, diseñados brillantemente, en mi opinión, en una especie de juego de espejos: Castells, escribe sobre las mujeres, un capítulo analítico en el que repasa eficazmente todos los datos más notables que traducen el gran cambio social ya experimentando por la condición de las mujeres, en el mundo occidental; Subirats, escribe sobre el inicio del cambio social de la masculinidad, motivado por los embates de las mujeres.

Ese es el carácter relacional de todo lo que concierne al Género, y ésta es la notable diferencia de un crucial proceso histórico: ellas están mucho más avanzadas tanto en lo fáctico como en el discurso producido (cómo no destacar la magnífica bibliografía que han producido los Estudios de las Mujeres, o los "gender studies", o cualquier otra etiqueta de las muchas que hay para este inmenso contingente de obras producidas y en continúa expansión). Ellos están en los inicios, además de haber sido obligados por la parte contraria, de la necesaria dialéctica de hombres y mujeres.

Hay dentro de la obra, una diferencia significativa de género (divertida, si se quiere, pues ya que los autores están hablando de género, y "hablando del Rey de Roma, por la puerta asoma"): 
- Marina Subirats ha escrito en un estilo muy otro que Manuel Castells. No ha dado ningún porcentaje (subyacen a la mucha investigación sociológica de género que ha realizado a lo largo de su dilatada carrera profesional). Ha puesto todo el corazón, toda su sensibilidad. Ha escrito mucho y bueno.

- Manuel Castells ha sido un "partenaire" excelente. No ha "chupado cámara", si tradujéramos la obra a lenguaje visual. Ha aportado una magnífica racionalidad (imasculina?).

He aquí una dimensión muy interesante de la obra, para ejercer el enfoque reflexivo y utilizarla como una especie de caso-estudio. Pero ello nos llevaría muy lejos, al terreno especializado de los estudiosos/as de las $\mathrm{Cc}$. Sociales.

Al público lector en general, debe interesarle el elogio sincero que hago de esta obra, su fácil lectura, su apasionante actualidad, su gran variedad de cuestiones, lo cual hace muy difícil analizarlas pormenorizadamente en una reseña, como ésta.

A los autores, agradecerles sinceramente el trabajo realizado, el esfuerzo de haber tratado de darnos lo mejor, en lo que más nos importa: el amor, pues de ello trata la obra (del amor, sus posibilidades/imposibilidades que está en la interrogante del título). Pero esto, lo descubrirá el público lector acompañando a los autores, machete en mano (en una especie de "thriller" de ideas y problemas) abriéndose paso por la frondosa espesura de la "selva de género", hoy.

Pese a las dificultades señaladas, voy a trazar diversas sendas de conocimiento que no son otras que las de mi lectura personal (aviso de sesgos) pero ¿qué no es personal? Guardando los límites de objetividad del contenido de la obra, sería muy tedioso para mí y aburrido para el lector, hacer un repertorio de todos y cada uno de los temas tratados por los autores: quasi un vademécum, además compacto por motivos de extensión de toda reseña. Todo un embrollo. Desecho esta vía, sigo por mis fueros. El dialogo se convierte en "trialogo" (Castells/Subirats/García de León) como sucedera también a todo lector/a que entre a participar en conversación tan amena, con los autores.

\section{"Ser mujer" (o los hallazgos/subrayados de Manuel Castells)}

Por evolución y por competición, se han generado en la Historia las dos figuras arquetípicas (rellenas de multitudes reales, aún hoy): el hombre unidimensional y la mujer multidimensional, reservándose en el juego de lo social (no lo olvidemos, un juego de dominan- tes y dominadas) para el hombre, el poder, la producción y la guerra; para la mujer, los espacios protegidos de las cocinas y las trastiendas de los gineceos (p. 16). He ahí la histórica división del trabajo que engendró dos culturas, dos psicologías, convertidas en esencias por la fuerza de la dominación y del peso de la historia. Describe Castells, con buena pluma, el mundo de las mujeres como: "una cultura propia hecha de observación subordinada y comportamiento estratégico a partir de una información más variopinta que la de los hombres y de los atributos en que tenían ventaja comparativa, desde la seducción hasta el socorro del frágil ego masculino" (p. 16).

Triste mundo de mujeres que sólo el Siglo XX ha visto felizmente cambiar, atención, sólo en el mundo occidental. La vocación internacionalista del feminismo no debiera cejar hasta ver este cambio extendido al resto de las mujeres del planeta (aunque ello choque con el tema, en mi opinión, de lo "interesadamente" políiticamente correcto, del multiculturalismo, etc. (velo sí, velo no, por dar un ejemplo).

Como afirma el autor: "Ia condición femenina ha cambiado más en tres décadas que en varios milenios" (p. 17). Y nosotras, somos muy conscientes y capaces de calibrar y paladear este enorme cambio social, asimismo capaces de defenderlo ante cualquier amenaza o retroceso, pues él es fruto de una compleja dinámica social, en la que nosotras hemos participado, a veces, con dolores como de parto; las más, con un empeño y una tenacidad encomiables (pienso en mi generación de mujeres profesionales españolas que nos criamos bajo el Franquismo y que supimos revolucionarnos hasta lo indecible con el feminismo y florecer en la Transición, pero también recuerdo a tantas mujeres que se quedaron en el camino, sufriendo la falta de realización - quasi esclavitud de ser "mujer objeto - bajo la dominación patriarcal).

He aquí otro punto de interés de esta obra que reseñamos: al ser el patriarcado un universal, puede ser leída y entendida por un público mucho más amplio que el español, aunque haya ciertas connotaciones singulares para el cambio mayúsculo de la sociedad española y, doblemente mayúsculo, en el caso de sus mujeres que en cierta manera, definen este cambio abismal y acelerado. Con todo, como toda la buena literatura de Género, reúne todos los ingredientes para traspasar fronteras.

En suma, "la larga sombra del patriarcado", como la llama Castells, comienza a difuminarse. 
Afortunadamente, hoy las mujeres occidentales podemos hablar desde cualquier tribuna pública, con esta asertividad y libertad de expresión: "El machismo mata, empobrece y atonta, por ese orden", Amelia Valcárcel dixit ${ }^{1}$ en el encuentro de Mujeres Líderes de España y Latinoamérica, celebrado en Madrid.

Realmente en Europa (por circunscribirnos a esta área del mundo occidental desde la que escribo y escriben los autores) vivimos una Edad de Oro de las mujeres. iQue gran privilegio ser europea, vivir en el Siglo XXI y ser una mujer profesional! podemos exclamar sin sonrojo y sin faltar a la verdad, quienes pertenecemos a este colectivo relevante tanto por número como por influencia en nuestras sociedades. Si, además de ello, somos de la generación que ha visto el Franquismo-la Transición, tenemos una perspectiva histórica del cambio social experimentado (objetiva y subjetivamente) auténticamente sobresaliente. Lo hemos visto todo, puedo exclamar. Podría empezar un relato, un día de estos, al modo siguiente: "Mi abuela era feudal, mi madre precapitalista, yo soy postmoderna". $Y$ el futuro es halagüeño: la tendencia es clara, el Siglo XXI será el siglo de la consolidación de la mujer. $^{2}$

\section{El quid del proceso de cambio}

Aquí radica el eje, en el cual los Estudios de Género (los de corte sociológico sobre todo) están centrando la atención en el mundo occidental. Sus preguntas fundamentales son: ¿Qué cambia y qué permanece? ¿Qué simplemente se altera transformándose. Como en el conocido "dictum" del Gatopardo: "que todo cambie para que todo quede igual". Tal vez sea esta la vía frecuentada por publicistas y el gran Mercado del mundo de la estética, la belleza, la moda que no quiere soltar a las mujeres de sus fauces manipuladoras, en las miles de formas de alienación que continuamente inventa para jóvenes o viejas. Para cada cual, su forma de alienación especializada.

¿Qué persiste? En una mañana veraniega, asistí a la lidia de este "toro", en la plaza mexicana de la gran UNAM, siendo su espada de fama internacional, Gilles Lipovetsky, con La tercera mujer. En olor de multitudes (auditorio más tres salas de videoconferencia) despachó este tema y vendió millares de ejemplares con su diagnóstico sobre él. Ello sería objeto de otra reseña. Sólo destacar aquí el gran interés que levanta este gran "tema de nuestro tiempo".

Hay una imagen que suelo pensar al respecto de lo dicho: la del azucarillo (en forma de paralelepípedo) que al contacto con un líquido se disuelve fácilmente, pero queda un núcleo duro, resistente, sin disolver que hay que forzar con la cucharilla y romperlo. Así hemos visto disolverse y desaparecer el valor y el tabú de la virginidad de las mujeres, en menos de dos décadas, al contrario, se ha impuesto sin gran resistencia social, el valor de que las jóvenes tengan relaciones prematrimoniales. ¿Y qué decir de la imagen social de "sus labores"? La caída y muerte del ama de casa en tanto que status dominante y recomendado para las mujeres, se ha disuelto totalmente. No hay mujer en la sociedad española actual que recomiende a sus hijas ser ama de casa, por el contrario, ser una mujer profesional es la imagen social hegemónica. Sin embargo, aquella fue la imagen impuesta y reproducida hasta la saciedad por el Franquismo que no ha aguantado los modestos embates del tiempo. Se ha disuelto, sin pena ni gloria.

¿Cual es el núcleo duro que resiste sin disolverse? Sin ambages: el poder. Y ello porque en el poder encuentra la masculinidad su eje, su identidad más profunda. ${ }^{3}$

Manuel Castells no es ajeno ni indiferente a este reto de detallar y analizar lucidamente ese fenómeno social. De este modo, dedica su capítulo en solitario a responder las preguntas que se ha hecho, reconociendo previamente el gran cambio social habido en la condición femenina. "Pero ¿en qué ha cambiado? ¿Y por qué?" En treinta páginas apretadas (p. 17-47) hace una síntesis inteligente y brillante dando su respuesta. Dejo a la curiosidad intelectual del futuro lector/a acudir a ella, dejando esta incógnita a modo de cebo mental.

\section{Un nuevo"corpus" de conocimiento/una nueva forma de escritura}

El Género como tema de "nuestro tiempo", candente, hemos escrito más arriba, pero no era así hace poco, especialmente entre nosotros. A finales de los años ochenta, en una investigación que hice en la que, entre otras tareas, estudié todos los programas de sociología de la UCM, en ninguno salía la palabra mujer.

Las Cc. Sociales españolas han tenido una ceguera total hacía la vertebración más importante de las sociedades: lo masculino/lo femenino. Alienadas-secuestradas por Leviatán y todos sus temas aledaños, muy influenciadas e ideologizadas por el marxismo, estaban muy despegadas de la realidad social, de la cual sólo los análisis de clase o de desigualdades 
sociales parecían acercarlas un tanto al mundo de lo real (ignorando que el género pasa radicalmente por dichas desigualdades).

"Leviatanescas" y "androcéntricas", las Cc. Sociales españolas (obsesionadas con la gran teoría política y todo lo concerniente al Estado y haciendo una gran elipsis de toda cuestión de género, por vía de una abstracta y asexuada Humanidad) han sido en un pasado reciente, escasamente cultivadoras de los temas de género. Ello es, en absoluto, caso único, antes bien creemos que es una especie de "universal" de todas las Cc. Sociales hasta los años 80.

Un grupo inicial de mujeres, reducido, entre las que se encuentra destacadamente la autora del libro - más Durán, Alberdi, Ballarín, Torns, Izquierdo, Astelarra, Rald, García de León, entre otras - y un muy reducido número de sociólogos: Garrido, Gil Calvo, Iglesias de Ussel y F. Ortega, entre otros pocos, fueron los/las pioneros/ as en cultivar los Estudios de Género, dentro del campo sociológico. Traspasando las barreras de su propia disciplina, la filosofía, es ineludible citar a Amorós y Valcárcel, teóricas del feminismo español.

Considero el acto de citar, el ejercicio de componer estas nomenclaturas, como un reto importante de los Estudios de Género, hoy, que deben estar ya en condiciones de hacer balances y dejar herencias intelectuales (tradiciones).

En la actualidad, sus cultivadores son numerosos y la perspectiva de género suele incorporarse obligadamente en toda investigación social, aunque la investigación no trate específicamente de hombres o mujeres. En esta especie de estado de la cuestión, observamos que los "Men's Studies" cuentan con escasos cultivadores aún entre nosotros. Frecuentemente, "pretenden analizar la temática de la masculinidad y terminan hablando de homosexualidad, sin cuestionarse si cabría ya tratar ese tema como una identidad más". ${ }^{4}$ Los estudios sobre "gays", "queers" proliferan en la literatura anglosajona actual.

Manuel Castells y Marina Subirats están dentro de un "corpus" de conocimiento de Género que se ha gestado colectivamente y en un lapso de tiempo sorprendentemente breve (sin duda, con el factor determinante, del empuje de las teóricas del movimiento feminista internacional). Esta obra que reseñamos tiene sus cimientos tanto en dicho "corpus" como en la dilatada investigación sociológica que han producido ambos autores independientemente. No es hablar por hablar, lo que hacen. Como advierte Subirats: su análisis corresponde a una "descripción sociológica", no a una crítica ética de la sociedad (p. 102).

En su haber está el romper con ese formalismo y rigidez que caracterizan a nuestras CC. Sociales, atreviéndose a ofrecernos este libro de "conversaciones" especializadas, casi inéditas en la bibliografía española, pero tan conocidas, sin embargo, tanto en la bibliografía francesa como en la anglosajona. Este es un dato muy novedoso que hay que apreciar en esta obra. A veces, conviene aligerar temas, adelantar problemas, señalar claroscuros, con soltura y urgencia (la que da una conversación entre especialistas) sin tener que esperar al momento supremo de entregar a la imprenta un tratado. En este sentido, Castells y Subirats están mostrándonos un nuevo camino y un nuevo modo de hacer, con esta forma de escritura.

Otro dato a destacar, es el de añadir el nombre de Castells a los grandes de la sociología que han escrito de mujeres (o de género): Bourdieu, Giddens, Touraine... Es el valor de lo simbólico que se añade a este reciente campo científico. Un buen refuerzo.

\section{"Ser hombre" (o los hallazgos/subrayados de Marina Subirats)}

Con buena escritura, la autora nos describe arquetipos tanto del pasado como del presente dentro del mandato o código cultural de "morir de hombría". Así, Subirats nos destila dicho código en el guerrero, en "el caballero de la triste figura", en los arquetipos fílmicos de los "rebeldes sin causa" o de "Gigante", en los que van desde Manolete a Ronaldinho, en "el ejecutivo agresivo global"... y, asimismo, sus acciones: la guerra, la lucha, el fútbol, los deportes de alto riesgo, la conducción temeraria. Pues bien, como en el caso de Castells (al tratar de las mujeres) Subirats se pregunta y describe a los hombres al hilo del cambio social experimentado por las relaciones de género y la sociedad en general. En este caso también, levantar la cartografía de lo que permanece o de lo que cambia es tarea obligada, igualmente registrar las curiosas reelaboraciones de las conductas de la masculinidad.

Una conclusión parece meridiana: "competir es la gran palabra de la masculinidad de nuestro tiempo, una palabra que ha pasado del deporte a la economía y de ella a invadir el conjunto de la sociedad. Competir, es la versión actual de pelear" (p. 98). Efectivamente, este impulso de la masculinidad va desde el taller mecánico a los ambientes más sofisticados del mundo intelectual. Competir, dominar, imponer, 
ser poderoso, es lo propio de los hombres aunque sea imponiendo la última palabra en el marco de una reunión académica, o siendo el que pone la última coma de un informe. En estos quehaceres ha quedado traducida el hacha de guerra, hoy, pero su impulso y finalidad son los mismo, quasi ancestrales.

De esta etnografía de la masculinidad, hemos dado cumplida cuenta, las mujeres académicas. Poco a poco, hemos ido traduciendo los códigos de nuestro entorno profesional inmediato, mayoritariamente masculino, con el saber de la propia cultura culta que se nos había negado hasta hace poco y también con la lucidez de las excluidas (o de las recién llegadas, de las "outsiders"). Posición ésta significativa y paradójicamente privilegiada: se ve mucho desde la orilla, por ejemplo el horizonte. Desde el centro, se está hasta tal punto embebido/encuadrado en tal posición que se ve poco. Valga esta forma metafórica de decirlo. En suma, las experiencias profesionales y vitales de las mujeres instruyen enormemente sobre el poder, es la visión del Otro, pero de otro que domina los instrumentos de la cultura, sus medios de análisis.

De todo ello nos habla incisivamente Marina Subirats. Tal vez en ella, como en toda mujer, hayan operado los mecanismos de aprehender la realidad de la "outsider", pese a su posición central en el campo sociológico español. Nada mejor que unas memorias intelectuales de género para esclarecer todos estos extremos, nada mejor que el enfoque reflexivo al respecto. Esa está siendo mi propuesta a mis pares, cayendo por lo general en la tierra baldía del fenómeno del tradicional antimemorialismo español, fenómeno no suficientemente estudiado, y menos, desde la perspectiva de género (a salvo de la excepción brillante y prácticamente única - significativamente y acorde con lo que acabamos de apuntar - de Anna Caballé, cuyo interés por la escritura del yo (biografía, autobiografía...) es la excepción que confirma la regla, en nuestro contexto. He ahí una interesante tarea de futuro para Marina Subirats, su biografía intelectual, o dándole un marco más general, la biografía como epistemología de género.

\section{El Género en claroscuro}

La obra, y sus autores, entran en un apasionado "in crecendo" cuando entran en su recta final, y abordan de lleno el tema del amor, sus posibilidades e imposibilidades.

La gran diferencia, en síntesis apretada de Subirats, es, en la actualidad que las mujeres pueden disociar los tres elementos del amor: primero, relaciones sexuales que no forzosamente desemboquen en la creación de una familia; segundo, pueden tener una familia más unas relaciones sexuales como algo que se disfruta o se consume, y, en tercer lugar, seguridad derivada de un puesto de trabajo que da independencia socioeconómica (p. 260).

Dicho esto, los problemas no hacen sino comenzar. ¿Dónde está lo simbólico? ¿Dónde está el sentido? ¿Dónde está lo trascendente? El planteamiento de los tres elementos anteriores (su realidad social, incluso) es una concepción muy mecanicista del horizonte vital, al menos el de las mujeres, por no decir materialista e ignorante de toda la antropología del género.

A duras penas, hemos dicho adiós a la tiranía patriarcal (a sus elementos más obvios). Ya no somos, ni seremos jamás, las "hijas de Bernarda Alba". También hemos dicho adiós a nuestro pasado ideal de la masculinidad, "Pepe, el romano" (macho por el que suspiraban y se mataban las hijas de Bernarda) por seguir en el estilo del plástico juego de los arquetipos (en nuestro caso, lorquianos) que Subirats ha desarrollado en unas páginas brillantes. Pero el mito del amor romántico, ese droga dura diseñada para la mujer, no ha dejado de hacer estragos. Una y otra vez, el mito toma marcha alimentada por Hollywood, y más aún, por los publicistas y diseñadores de moda.

El amor romántico toma a su cargo la dimensión trascendente de manera creciente, "en la medida que otras dimensiones se han perdido" (por ejemplo, la religión) opina Subirats, a lo cual responde Castells: "esto es muy interesante, la idea de que el amor es la privatización de la religión" (p. 261).

He escrito los "claroscuros del género", porque las cosas dejan de estar ya tan claras una vez que se ha logrado la nada desdeñable plataforma de conquistas que el feminismo ha promovido para lograr una condición social femenina autónoma. Nada más ni nada menos. Lograda la base socioeconómica, el paso histórico de la mujer objeto a la mujer sujeto (por primera vez en la Historia de la Humanidad, no lo olvidemos) ¿Qué queda?

La familia igualitaria, ya realidad, y laboratorio experimental para el futuro, es sobre todo la de dobles profesionales igualados que suele corresponder a las clases medias urbanas. En ella se dan los ingredientes excelentes de cultura + dinero, los cuales son capaces de generar una "economía interna" muy estimulante. Establecer un nuevo pacto, por fin "entre 
personas que se respetan por igual", termina la obra, diciendo Subirats.

Quizá esa especie de "paraíso a lo humano" que puede constituir la pareja igualitaria, tenga muy al acecho el divorcio, su gran debilidad. Por ello, el refuerzo institucional (la economía interna que decía) no viene nada mal, para reforzar la familia, ya que como decía Engels, en su clásica y archiconocida obra sobre el origen de la familia: "La crisis de la pareja es consecuencia de la monogamia en su sentido etimológico. Cuanto más se basa sólo en el amor, más probable es que acabe rompiéndose".

Para el futuro ya inmediato, quedan por construir desarrollos sociales de género mucho más sofisticados. En ello, las mujeres estamos mucho más entrenadas, como dominadas que hemos sido, a la conquista de nuestra liberación. El epicentro del cambio social está ahora en los hombres, que han estado ajenos a esta necesidad histórica de cambio que se les ha impuesto casi sin percatarse, como dominadores "no question". Esta es una idea fuerza que comparto totalmente con Subirats: "La transformación cultural tiene que afectar básicamente a los hombres. Los hombres tienen que dejar esta coraza que les seguimos fabricando y entrar en una comprensión distinta de la vida y de la realidad" (p. 305).
Todo ello, lo que hemos relatado, es una tarea titánica, en la que habrá que "robar el fuego a los dioses". No sólo sociólogos, sino también antropólogos, psicólogos, psicoanalistas, filósofos, filólogos... y toda una caterva de especialistas, tendrán que intervenir en una tarea histórica: la descolonización del imaginario de género. Ese es el reto, una vez conseguida la igualdad social.

\section{Notas}

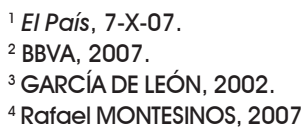

\section{Referencias bibliográficas}

BBVA. Actividad y territorio. Un Siglo de cambios. Informe de la Fundación BBVA y el IVIE, 2007.

GARCÍA DE LEÓN, María Antonia. Herederas y Heridas. Sobre las élites profesionales femeninas. Madrid: Catedra, 2002.

MONTESINOS, Rafael. Perfiles de la masculinidad. Madrid: UAM-1/Editorial Plaza y Valdés, 2007.

María Antonia García de León Álvarez Universidad Complutense de Madrid 